\title{
“NOSES AND EYES": NURSE PRACTITIONERS IN NEW ZEALAND
}

Donna Diers, RN, PhD, FAAN, Annie W. Goodrich Professor Emeritus of Nursing, School of Nursing, Yale University, Connecticut, USA

This invited article is based on a presentation given to the first conference of Nurse Practitioners in New Zealand, Auckland, 20 October, 2007.

\begin{abstract}
Principles for understanding and evolving nurse practitioner practice, politics and policy are distilled from 40 years of experience in the United States and Australia. The issues in all countries are remarkably similar. Some historical and conceptual grounding may assist the continuing development of this expanded role for nursing in New Zealand.
\end{abstract}

Key Words: Nurse practitioners, advanced nursing practice, nursing and policy.

\section{Introduction}

Not long ago, I took a tour of the Parliament buildings in Wellington. In the well of the House, the guide said something about how they tally the "noses and eyes." I had this Harry Potter vision of guys in black morning suits dashing about counting noses and eyes. "No's" and "ayes," of course. My American ears heard something different. This experience reminded me never to take anything for granted in international understanding. Nevertheless having been in the company of nurse practitioners (NPs) since the very first of them emerged in the United States (US) in the late 1960 s, I offer a few principles that might transcend national borders, political systems and accents.

\section{Principle \# 1: Context is Everything}

As one of my country's old time politicians, the late Senator Tip O'Neill said, "All politics are local." New Zealand (NZ) has a lovely island mentality: we're all in this together. There is a common sense of the fragility of the ecology, the location on the tectonic plate, the instability of volcanoes and the vulnerability to tsunami, and the history of the Treaty of Waitangi and its violations. In a small country, in a policy context, everybody knows everybody. That's what "retail politics" is all about knowing the constituency so well that one can appeal to its special interests.

Diers, D. (2008). "Noses and eyes": Nurse practitioners in New Zealand. Nursing Praxis in New Zealand, 24(1), 4-10. 
Nurse practitioners are probably only two degrees of separation from those whose support and co-operation is needed. The constituency might be the Ministry of Health itself, or the Nursing Council or the College, or the administration and management of a District Health Board (DHB). Energy spent on getting to know those with whom one will have to negotiate is energy well spent. This is not the kind of work nurses find easy but it is the way political work gets done.

Because you are part of this small country, you harbour its values, concerns, and intentions. You all speak the same language, and I don't mean English and Maori. You are all in this together. You have the Treaty as a beacon.

\section{Principle \# 2: Patient safety comes before professional ambition and also after}

One of the things we did wrong in the US (and Australian NP advocates did wrong as well) was to let the political rhetoric turn from the needs of patients to competition among health professionals. Across the world, physicians have managed to stake out their rhetorical claim to own all of health care, which makes the rest of us appear to be ungrateful usurpers, pretenders to the throne of medical hegemony. There are two related lessons. First, we need not only to develop strong educational and practice standards, but also we need to advertise them in the context of patient safety. You have done that here in the portfolio and viva system, grounding NP work in post basic education.
Secondly, such standards must be standards for nurse practitioner practice, not for some watered down version of medical practice. Organised medicine will wish to put their rhetoric into play; that must be resisted and countered. One of the heroines of the NP movement in the US is an attorney, Barbara Safriet, who has written two definitive monographs on administrative law as it applies to nurses in expanded roles: Health care dollars and regulatory sense, and Closing the gap between can and may in health-care providers' scopes of practice: A primer for policymakers (Safriet, 1992, 2002). Barbara has been the leading force in a very important report from the Pew Charitable Trusts who put together a Task Force composed of representatives of the six federations of State Boards of regulation in nursing, medicine, social work, occupational therapy, physical therapy and pharmacy. This is a peculiarly US arrangement: every state has a State Board (like NZ's Nursing Council) that licenses healthcare professionals, one aching state at a time, using standard national examinations. There are organisations that pull together all fifty one of such State Boards into a Federation. A gathering of the six Federations is quite a powerful representation, even if there are only six people in the room.

Under Barbara's leadership, this cabal delivered itself of a policy document (Changes in Health Care Professions' Scope of Practice: Legislative Considerations, 2007) aimed at legislators. It states forthrightly, "The question that healthcare professionals must answer today is whether their 
profession can provide [a service] in a safe and effective manner. If an issue does not address this question, it has no relevance to the discussion" (p. 3).

The Executive Summary goes on, "The argument for scope of practice changes should have a foundational basis within four areas: (1) an established history of the practice scope within the profession; (2) education and training; (3) supporting evidence; and (4) appropriate regulatory environment" (p. 4).

Then it sounds the charge, "If a profession can provide supportive evidence in these areas, the proposed changes in scope of practice are likely to be in the public's best interest" (p. 4). (Emphasis added)

That last trumpet blast changes the playing field from historical ownership of pieces of scope of practice to evidence.

\section{Principle \# 3: Data speak louder than words}

Where to find evidence? It will not be in Cochrane Collections, reviews of published studies, (preferably randomised controlled clinical trials) as I learned painfully in Australia. The US, Canadian or United Kingdom (UK) literature did not help the NP advocates there. "We're not like that," was the reaction, ignoring the fact that while there are indeed large differences in the regulatory environments across countries, patients who need care are a lot the same. The real issue is whether it is possible to find NP practice in existing data systems at local levels (Diers, 2007). These data have credibility in retail politics in a way the international literature, no matter how carefully peer reviewed, does not. In the US, this has been a problem we did not recognise as early as we should have. The only reliable electronic data about service delivery in the US comes from the billing systems; that is simply the way our healthcare data systems are built.

We succeeded in putting NPs in primary care and other sites and they seemingly disappeared. There was no box on the billing form to check what kind of clinician had been involved in the care. In states with physician collaboration or supervision requirements for NPs, the billing forms had to be co-signed, so the visit was treated as a physician visit. Even now, when NPs can bill on their own, they can only be paid (by most payers) at a fraction of the physician rate - currently $85 \%$. This creates an incentive for the practice or organisation to bill visits at the physician rate, which makes the physician the provider of record. This, of course, is fraud. The result was that even today in the US it is very difficult to get good data on the work of nurses in advanced practice from existing administrative data systems.

The learning from the above is: make sure nursing's work can be captured in existing electronic data systems. All that is needed is to have a data element for the treating clinician. The other data elements to link NP activity with outcome are already there: patient identifier as medical record or visit number, date of service, and type of service. I looked up the data dictionary for the National 
Non-Admitted Patient Collection (NNPAC) on the New Zealand Health Information System (NZHIS) website. As of September 2007, the only "health provider types" available were "doctor", "nurse" and "other" (NZHIS, 2007). You may want to fix this in the interest of being able to track NP work.

\section{Principle \#4: If the patients are invisible, so will be the clinicians}

The history of NP work is that we moved into the areas of greatest need. In the US this was first with poor children in the mountains of Colorado. In Canada it was in the far north, on native people's reservations. In Australia it was in the outback and in the Corrections system. In NZ it has been with people, including babies, with chronic illnesses. Clearly these are where holes in the healthcare delivery system exist. Moreover they are exactly the arenas of least resistance because nobody else wants seriously to be there. (It amuses me in dark moments to note that the famous Royal Flying Doctor Service in the remotest outback of Australia is actually staffed by nurses). One might attribute this to the unfairness of a social consciousness that can only recognise doctors. I find it less maddening to think that because when the patients cared for do not count, neither will their caregivers. The mentally ill, the indigent mothers, the chronically ill, the destitute in the outback, the victims of a so-called civilised society such as our Native Americans or perhaps your Maori, the war wounded, the kids in hidden valleys in Colorado - these are the people who get ignored, deliberately or unthinkingly. And there we are. It requires tenacious investigative reporters or real social reformers to discover this work. It doesn't make headlines; it is not sexy.

\section{Principle \# 5: Make the work public}

The work needs to be made public not only in the public community, from which political support might come, but also in the academic community. In $\mathrm{NZ}$ you have a rich tradition of qualitative research methods including discourse analysis, which is about digging into the meanings of meaning. There is much to be understood about the rhetoric of nursing and advanced practice nursing - the ways in which nursing is characterised in public documents, in the media, and in whatever sources to which Ministries of Health, professional associations or the public pay attention. In your portfolio and viva process NZ NPs have a wondrous data source to be mined, whether by discourse analysis or other qualitative methods. These sources provide a natural sample of NP work that could usefully be mined for public presentation. One example is Helen Snell's submission on the therapeutic products and medicines bill (Snell, 2007). She concentrates a story on the idiotic inefficiency that present practice requirements for physician supervision pose for individual treatment titrations of insulin in a busy diabetes specialty practice. There must be many more such riveting stories. Do something with them. 


\section{Principle \# 6: There is no shame in hiring expertise}

It has been my experience that we nurses think we have to do clinical practice and research and scholarship and management and administration and advocacy and citizenship, in lonely, exhausted splendour. We live on volunteers in our professional organisations. Meanwhile, medical associations hire public relations types. They, not the medicos, write the op-eds and letters to the Editor. They write the public testimony, which is why the public testimony is so often at odds with "on the ground" work between NPs and physicians. Nursing has also been hesitant to hire lobbyists or media manipulation people - it feels dirty. But politics is a skill and so is "spin" and there are experts for hire. We don't have to like it, but if we are serious about making NP work accessible and valued by the public and by policy makers, we may need to make that a priority investment.

\section{Principle \#7: Some things will never change}

Recently, I came across an archivable file folder from what we thought then was the heyday of NPs in our complicated University teaching hospital primary care centre (PCC). I was then Dean of the School of Nursing and had negotiated a number of NP positions that were jointly funded by the Hospital and the University. There were four NPs in the adult Primary Care practice who reported for their practice up to the Director of Nursing, and for their scholarship to the School of Nursing, just as physicians had dual reporting relationships to the Chief of Staff in the hospital and the School of Medicine.

In this folder lurked a whingeing letter that the new Medical Director of the PCC had written to the Director of Nursing (Black, 1981). The context was that the Medical School had acquired a major grant from a high profile Foundation to train up physicians in primary care, then a new specialty in medicine. Dr Black recites a bit of history: “... before 1975, only PGY II (second year house staff) saw medicine out-patients ... . Two NPs were hired to help ... follow some particularly difficult patients who especially needed to relate to one provider." Get it? "To help" for "especially difficult patients." He goes on: “... in 1975, ... two additional NPs were added to our staff, all of whom had joint appointments in the School of Nursing and were dedicated to personally managing a panel of patients with very little, if any, physician supervision. Now ... we have added an additional physician to our staff and our physicians have made a strong commitment to care personally for the patients in the Practice. It is clear to me that we no longer need NPs to function as they have in the past and that their role must evolve to meet the needs of the Practice." (emphasis added)

He goes on: "As I see it, the major need for NPs is to provide care for walk-in patients who cannot be seen by their primary provider at the precise time that care is required." This would mean NPs, originally hired for continuity of care, would instead simply fill in for unavailable physicians, seeing, by the way, the most urgent patients, those 
who are unselected, undiagnosed and sick! Then, he delivers himself of the opinion that NPs should have a "single allegiance" so that "the goals of the School of Nursing should not be interfering with the success of the Practice and the wishes of the Department of Internal Medicine." (emphasis added) That letter is 26 years old.

Of course, the School of Nursing did not give up its interest in primary care practice and we added yet another NP and it worked wonderfully. There was a critical mass of NPs, they did have a "single alliance" which was to nursing and the School of Nursing. They were able to work out their practice relationships from a position of equality. Physician arrogation will not change easily or quickly. It will survive changes in leadership in other disciplines (as happened for us). Those who care about patients having the very best service from interdisciplinary practice will have to hang in there through generations of our own leaders.

\section{Principle \# 8: If the previous Principle was that some things never change, this one is, and some things do}

In Pennsylvania, the Governor has signed into law the first of a series of bills in his comprehensive plan to provide greater access to high quality care for all Pennsylvanians at affordable costs. A critical building block in his health reform plan is to utilise fully the current professional health care workforce in the state. A big chunk of that workforce is NPs, nurse-midwives and nurse anaesthetists (J. Haebler, personal communication, July 26, 2007). The new law in Pennsylvania removes previous barriers to full scope practice for NPs and in the words of the law says they may "provide acute illness or minor injury care or management of chronic illness in the same manner as physicians ... so long as those activities fall within their specialty certification and scope of practice." Insurers are required to include in all provider networks (like NZ's Primary Health Organisations) NPs, clinical nurse specialists working in primary care and nurse-midwives. This bill is important for two reasons: (1) Pennsylvania is a big and conservative state and if it can move, other states can too; and (2) the bill positions nursing and advanced practice nursing as part of the solution to the manpower shortage.

When NP work started in the US, our national professional organisation, the American Nurses' Association (ANA), resisted (Ford, 1992). Our ANA also resisted the efforts of nurse-midwives and nurse anaesthetists (Diers, 1992). That has meant that the efforts to develop nursing as primary care and as "advanced nursing practice" have splintered us now into a nearly uncountable number of different organisations, to say nothing of different licenses, depending upon the state. Happily you brilliant Kiwis have done what no other country has done: created the potential for a collaborative strategy that includes all of the major players including the New Zealand Nurses Organisation (NZNO), the College of Nurses Aotearoa, the National Council of Maori Nurses, the New Zealand College of Mental Health Nurses and the Nurse Executives of 
New Zealand. This is so unusual as to be sui generis in nursing in the world. It leads to the last principle.

\section{Principle \#9: Celebrate success}

There is so much hard, grinding work that goes on behind the scenes, work that never gets known, much less applauded. It is lonely out there in
Dunedin and Hawkes Bay. It is also lonely in California, Connecticut and Colorado. Would not it be fun to have a worldwide NP website that could report on common problems and uncommon solutions? My nose and my eyes tell me that nurse practitioneering in $\mathrm{NZ}$ is muscular, subtle, original and leading the world.

\section{References}

Black, H. (1981, April 21) Letter from Henry Black to Rachel Rotkovitch. Yale School of Nursing archives. Accession 2007, file "YIMA".

Changes in Health Care Professions' Scope of Practice: Legislative Considerations. (2007). Retrieved September 27, 2007 from https://www.ncsbn.org/ ScopeofPractice.pdf

Diers, D. (1992). Nurse-midwives and nurse anesthetists: The cutting edge in specialist practice. In L. Aiken, \& C. Fagin (Eds.), Charting nursing's future: Agenda for the 1990's (pp 159-180). Philadelphia: Lippincott.

Diers, D. (2007). Finding midwifery in administrative data. Journal of Midwifery and Women's Health, 52(2), 98-105.

Ford, L.C. (1992). Advanced nursing practice: Future of the nurse practitioner. In L. Aiken, \& C. Fagin (Eds.), Charting nursing's future: Agenda for the 1990's (pp. 287-299). Philadelphia: Lippincott.

New Zealand Health Information System. (2007). National non-admitted patient collection. Retrieved September 27, 2007 from https://www.nzhis.govt.nz

Safriet, B. (1992). Health care dollars and regulatory sense. Yale Journal on Regulation, 9, 417-487.

Safriet, B. (2002). Closing the gap between can and may in health-care providers' scopes of practice: A primer for policymakers. Yale Journal on Regulation, 19, 301-334.

Snell, H. (2007, February 7). Submission to the government Administration Select Committee - Therapeutic Products and Medicines Bill, New Zealand. 